\title{
Peer-reviewed research
}

\section{Pandemics and the Asia-Pacific Islamic Stocks}

\author{
Afees A. Salisu ${ }^{1}$ a Abdulsalam Abidemi Sikiru $^{2}$ \\ ${ }^{1}$ Centre for Econometric \& Allied Research, University of Ibadan, Nigeria, ${ }^{2}$ Research and Statistics Department, West African Monetary Agency, Sierra \\ Leone. \\ Keywords: predictability, hedging, pandemics, conventional stocks, islamic stocks \\ https://doi.org/10.46557/001c.17413
}

\section{Asian Economics Letters}

Vol. 1, Issue 1, 2020

In this paper, we examine the potential of the Asia-Pacific Islamic stock market to serve as a good hedge against uncertainty due to pandemics and epidemics (UPE). Relying on a new dataset for UPE, we find evidence in favour of the hedging potential of the Asia-Pacific Islamic stocks against UPE albeit with lower hedging effectiveness during the COVID-19 pandemic. Further, results show improved out-of-sample forecasts of stock returns when using the UPE predictor.

\section{INTRODUCTION}

In this paper, we examine the potential of the Asia-Pacific Islamic stock market to serve as a good hedge against uncertainty due to pandemics and epidemics (UPE). The study's motivation has roots in the extant literature, which suggests a strong connection between the COVID-19 pandemic and conventional stocks (see, for example, Al-Awadhi et al., 2020; He et al., 2020; Phan \& Narayan, 2020; Salisu \& Akanni, 2020). Yet, the responsiveness of Islamic stock markets to COVID-19 seems relatively understudied (Ashraf et al., 2020). This is surprising given the vast literature on Islamic stock markets and the relevance of Islamic stocks in active portfolios (see Narayan \& Phan, 2019). The resilience of Islamic stock markets during the global financial crisis is another motivation for this study; see Masih et al. (2018) for a review. Inspired by these studies, we hypothesize that the Asia-Pacific Islamic stock market is likely to serve as a good hedge ${ }^{1}$ against UPE. We explore the link between the two variables by using the recent datasets on UPE developed by Baker et al. (2020). ${ }^{2}$ While the interest is on the AsiaPacific Islamic stock market, for completeness, the empirical analysis is also replicated for the conventional market. Additional analysis is also carried out to establish the predictive content of UPE for out-of-sample predictability of stock returns. Thus, the study's findings have implications for portfolio diversification strategies, particularly for investors seeking to maximize returns in the Asia-Pacific region.

Using a predictability model suitable for the variables of interest (see Westerlund \& Narayan, 2012, 2015), we find strong evidence in support of the hedging potential of the
Asia-Pacific Islamic stocks during pandemics and epidemics compared to conventional stocks. The results supporting this conclusion pass a battery of tests for predictability analysis. These findings make three contributions to the literature. First, it extends the literature on the response of financial markets to the COVID-19 pandemic to capture the Islamic stock markets, which surprisingly seems to have received limited attention to-date. The second contribution relates to the assessment of the hedging potential of Islamic stocks to UPE. Following our study, hedging potential during COVID-19 can be tested in other markets using different assets. Finally, we test whether exploiting the predictive contents of UPE can enhance the out-of-sample forecasts of stock returns. The rest of the paper is structured as follows. Section II discusses data and methodology. Results and discussions appear in Section III. The final section concludes.

\section{DATA AND METHODOLOGY}

We utilize daily data for the predictor series based on the recently developed measure of UPE by Baker et al. (2020). Data are obtained from the FRED database of the Federal Reserve Bank of St. Louis. For the predicted series, we utilize daily data of two composite stock indices: (i) the conventional stock price index proxied by the Standard and Poor's (S\&P) Dow Jones Composite Average stock index (DJ$\mathrm{CA}$ ); and (ii) the Asia-Pacific Islamic stock price index proxied by the Dow Jones Islamic Market Asia/Pacific index (DJIM). The DJIM index measures the performance of equity stocks traded in 15 countries from the Asia/Pacific region. Daily data on the two predicted series are obtained from the Bloomberg terminal. The full data scope ranges from 8/31/

\footnotetext{
a A. A. Salisu is a corresponding author. Contact details: Centre for Econometric \& Allied Research, University of Ibadan, Ibadan, Nigeria. Email: aa.salisu@cear.org.ng

1 The intuition behind the use of hedging here is drawn from the inflation hedging literature, where an asset that serves as a good hedge against inflation is expected to retain or increase in value as inflation increases (see Arnold \& Auer, 2015). However, the interpretation here slightly differs from the conventional inflation hedging since the UPE indicator cannot play the role of inflation in terms of the relationship between real and nominal variables. Thus, in this paper, there are three possible outcomes in relation to UPE. Assume the coefficient on UPE is " $b$ ", then the three possible outcomes are: (i) $b>0$ (high hedge, such that the return increases with $U P E$ ); (ii) $b<0$ (worst hedge, where return reduces with $U P E$ ); and (iii) $\mathrm{b}=0$ (low hedge, where return remains unchanged with $U P E$ ).

2 Using the same measure, Salisu \& Adediran (2020) find a strong connection between energy risk and pandemics. An alternative index by Salisu \& Akanni (2020) confirms the vulnerability of conventional stocks to the COVID-19 pandemic.
} 
2010 (post global financial crisis period) to 9/15/2020. From this sample, we draw the COVID-19 period. The analyses are conducted using both the pre-COVID-19 sample $(8 / 31 / 2010$ to $12 / 31 / 2019$ ) and the sample covering the COVID-19 pandemic (01/01/2020 to $9 / 15 / 2020)$. We also control for an additional predictor, oil price (using the West Texas Intermediate crude oil price ${ }^{3}$ ), given evidence of its strong connection with the stock market (Salisu et al., 2019, among others; see Smyth \& Narayan, 2018).

In line with the risk-return hypothesis, we construct a predictive model that quantifies the response of the AsiaPacific Islamic stock market as well as the conventional market to UPE. During turbulence, a number of studies have established a negative correlation between risk and market returns for conventional stocks (see Al-Awadhi et al., 2020; He et al., 2020; Phan \& Narayan, 2020; Salisu \& Akanni, 2020) and a positive correlation for Islamic stocks (see Masih et al., 2018). To circumvent any potential endogeneity bias and persistence effect, the predictive model takes the form (see Westerlund \& Narayan, 2012, 2015):

$$
r_{t}=\alpha+\sum_{i=1}^{5} \lambda_{i}^{a d j} U P E_{t-i}+\gamma\left(U P E_{t}-\rho_{0} U P E_{t-1}\right)+\eta_{t}
$$

where $r_{t}$ is the log return of stocks price index (of either Islamic or conventional market); UPE has been previously defined; $\eta_{t}$ is zero mean idiosyncratic error term; the coefficient $\lambda_{i}^{a d j}$ measures the response of stock returns to UPE; and we allow a maximum of five lags given the 5-day daily data frequency. Five lags also allow us to capture more dynamics in the estimation process. Thus, the hedging potential of a market against UPE is evaluated using the Wald test for joint significance. The considered market is likely to at least retain the value of its returns, on the average, in the face of $U P E$, if $\sum_{j=1}^{5} \lambda_{i}^{\text {adj }} \geq 0$; otherwise, it is more likely to be vulnerable. All the variables are pre-weighted with $1 / \hat{\sigma}_{\eta}$ to account for conditional heteroscedasticity effect and we refer readers to Westerlund \& Narayan $(2012,2015)$ on the estimation procedure for Equation (1).

\section{MAIN FINDINGS}

We begin the analysis with basic preliminary statistics and the results are presented in Table 1 . We see higher returns and lower volatility in Islamic stocks relative to the conventional stocks during the COVID-19 pandemic while both index returns are stationary. The presence of salient features in the data, such as persistence, endogeneity bias, and conditional heteroscedasticity as depicted in Table 1 further validates the choice of our predictability approach and model. In the main analysis, we begin interpretation with the predictability results which show the response of both Islamic and conventional stock markets of the AsiaPacific region to UPE (see Panel A of Table 2). We find a significant positive relationship between Islamic stock returns and UPE during the pre-COVID-19 period implying that higher returns can be achieved with higher incidence of pandemics and epidemics. However, the coefficient is not significant for the conventional stock market during the same period and the outcome remains the same even after controlling for oil price. The outcome further confirms the evidence in the literature about the resilience of the
Islamic stock market to crises relative to the conventional stock market. Nonetheless, the hedging effectiveness of the Islamic stock market declines during the COVID-19 pandemic given the positive but insignificant coefficient of the $U P E$ index while the sign is negative for the conventional stock market. Overall, on average, we find evidence of higher hedging potential for the Asia-Pacific Islamic stocks against $U P E$ relative to the conventional market.

Additional analysis is rendered to evaluate the out-ofsample predictive content of the UPE index and this is done for multiple out-of-sample forecast horizons, namely a 10-day, a 20-day and a 30-day ahead forecast horizon using a $75 \% / 25 \%$ data split. We use the historical average (constant returns) model that ignores the UPE index as the baseline model, and its relative performance with the UPE-based models ("Without control" and "With control") is evaluated using the Clark \& West (2007) test. The results are presented in Table 2 (Panel B for the in-sample forecasts and Panels C \& D for the out-of-sample forecasts). We find that exploiting the information contained in the UPE index as well as oil price can improve the out-of-sample predictability of stock returns. In this paper we do not test the economic significance of these forecasts. We set this aside for future research.

\section{CONCLUSION}

In this study, we examine the resilience of the Asia-Pacific Islamic stock market as well as the conventional stock market to uncertainty due to pandemics and epidemics. Using a predictability technique that accommodates the salient features of the data, we find evidence in favour of the hedging potential of the Asia-Pacific Islamic stocks during pandemics and epidemics albeit with lower hedging effectiveness during the COVID-19 pandemic. Further results show the significance of exploiting the information about $U P E$ as well as other global factors, such as the oil price, in the out-of-sample predictability of stock returns.

\section{Acknowledgement:}

I would like to thank the Editor and the anonymous referee for many helpful comments. However, the usual disclaimer applies.

Submitted: September 24, 2020 AEDT, Accepted: October 01, 2020 AEDT 
Table 1: Preliminary results

\begin{tabular}{|c|c|c|c|c|c|c|}
\hline \multirow[t]{2}{*}{ Statistics } & \multicolumn{3}{|c|}{ Pre-COVID sample (8/31/2010 to $12 / 31 / 2019)$} & \multicolumn{3}{|c|}{ COVID-19 sample (01/01/2020 to 9/15/2020) } \\
\hline & $\begin{array}{l}\text { Islamic } \\
\text { stocks }\end{array}$ & $\begin{array}{l}\text { Conventional } \\
\text { stocks }\end{array}$ & UPE & $\begin{array}{l}\text { Islamic } \\
\text { stocks }\end{array}$ & $\begin{array}{l}\text { Conventional } \\
\text { stocks }\end{array}$ & UPE \\
\hline Mean & 0.022 & 0.042 & 0.386 & 0.082 & -0.009 & 20.956 \\
\hline Std. Dev. & 0.856 & 0.851 & 0.837 & 1.392 & 2.664 & 15.000 \\
\hline ADF & $-31.447^{a * * *}$ & $-50.774^{a * * *}$ & $-13.079 a * * *$ & $-11.7120^{a * * *}$ & $-7.359^{a * * *}$ & $-11.742^{b * * *}$ \\
\hline $\mathrm{GARCH}$ & $-44.169^{a * * *}$ & $-46.956^{a * * *}$ & $-55.871^{\mathrm{a} * * *}$ & $-11.009^{a * * *}$ & $-12.782^{a * * *}$ & $-22.887^{b * *}$ \\
\hline $\mathrm{ARCH}(2)$ & $48.582^{* * *}$ & $212.141^{* * *}$ & $31.197^{* * *}$ & $14.658^{* * *}$ & $22.937^{* * *}$ & $4.707^{* *}$ \\
\hline $\mathrm{ARCH}(4)$ & $40.704^{* * *}$ & $119.030^{* * *}$ & $27.079^{* * *}$ & $7.603^{* * *}$ & $13.067^{* * *}$ & $2.367^{*}$ \\
\hline $\mathrm{ARCH}(6)$ & $29.356^{* * *}$ & $83.602^{* * *}$ & $25.157^{* * *}$ & $5.641^{* * *}$ & $12.355^{* * *}$ & $1.820^{*}$ \\
\hline Q-stat (2) & $8.3683^{* *}$ & 0.2196 & $31.551^{* * *}$ & 4.467 & $11.571^{* * *}$ & $7.993^{* *}$ \\
\hline Q-stat (4) & $20.244^{* * *}$ & 5.9172 & $104.13^{* * *}$ & 6.762 & $14.157^{* * *}$ & $10.109^{* *}$ \\
\hline Q-stat (6) & $22.676^{* * *}$ & $19.272^{* * *}$ & $188.54^{* * *}$ & 8.950 & $20.101^{* * *}$ & $13.381^{* *}$ \\
\hline $\mathrm{Q}^{2}$-stat (2) & $107.32^{* * *}$ & $440.60^{* * *}$ & $68.541^{* * *}$ & $32.881^{* * *}$ & $44.548^{* * *}$ & $10.067^{* *}$ \\
\hline $\mathrm{Q}^{2}$-stat (4) & $219.17^{* * *}$ & $671.60^{* * *}$ & $140.93^{* * *}$ & $46.850^{* * *}$ & $61.188^{* * *}$ & $10.232^{* *}$ \\
\hline $\mathrm{Q}^{2}$-stat (6) & $276.68^{* * *}$ & $842.98^{* * *}$ & $225.76^{* * *}$ & $62.724^{* * *}$ & $85.091^{* * *}$ & $11.469^{*}$ \\
\hline Persistence & - & - & $0.610^{* * *}$ & - & - & $0.903^{* * *}$ \\
\hline Endogeneity & $\begin{array}{l}-0.002 \\
(0.023)\end{array}$ & $0.003(0.023)$ & - & $\begin{array}{c}-0.026^{* *} \\
(0.013)\end{array}$ & $-0.014(0.025)$ & - \\
\hline Nobs & 2366 & 2366 & 2366 & 178 & 178 & 178 \\
\hline
\end{tabular}

Notes: Symbols $* * * * * * *$ denote statistical significance at $1 \%, 5 \% \& 10 \%$ levels, respectively; superscripts a and b indicate that the variable is stationary in levels and first differences, respectively. The GARCH-based unit root test is the one proposed by Narayan and Liu (2015) and it is considered an alternative to the Narayan \& Popp (2010) test due to the data frequency used in this study (see also Salisu \& Adeleke, 2016). Both unit root tests are conducted with a constant and a time trend. Details about the persistence and endogeneity tests are contained in Westerlund \& Narayan $(2012,2015)$. 
Table 2: Predictability and forecast evaluation results

\begin{tabular}{|c|c|c|c|c|c|c|}
\hline \multicolumn{7}{|c|}{ Panels A: Predictability results } \\
\hline & \multicolumn{3}{|c|}{ Pre-COVID sample (8/31/2010 to $12 / 31 / 2019)$} & \multicolumn{3}{|c|}{ COVID-19 sample (01/01/2020 to 9/15/2020) } \\
\hline & \multicolumn{2}{|c|}{ Islamic stocks } & Conventional stocks & \multicolumn{2}{|c|}{ Islamic stocks } & Conventional stocks \\
\hline $\begin{array}{l}\text { Without } \\
\text { control }\end{array}$ & \multicolumn{2}{|c|}{$\begin{array}{c}0.3760^{* * *}(0.1276) \\
{[2.9455]}\end{array}$} & $\begin{array}{c}0.0884(0.1134) \\
{[0.7793]}\end{array}$ & \multicolumn{2}{|c|}{$0.0207(0.0478)[0.4328]$} & $\begin{array}{c}-0.0177(0.0631) \\
{[-0.2796]}\end{array}$ \\
\hline With control & \multicolumn{2}{|c|}{$\begin{array}{c}0.3273^{* * *}(0.1114) \\
{[2.9385]}\end{array}$} & $\begin{array}{c}0.1069(0.1111) \\
{[0.9624]}\end{array}$ & \multicolumn{2}{|c|}{$0.0036(0.0148)[0.2421]$} & $\begin{array}{c}0.0022(0.0197) \\
{[0.1124]}\end{array}$ \\
\hline Nobs & \multicolumn{2}{|c|}{2366} & 2366 & \multicolumn{2}{|c|}{178} & 178 \\
\hline \multicolumn{7}{|c|}{ Panel B: In-Sample forecast evaluation } \\
\hline & \multicolumn{3}{|c|}{ Pre-COVID sample (8/31/2010 to $12 / 31 / 2019)$} & \multicolumn{3}{|c|}{ COVID-19 sample (01/01/2020 to 9/15/2020) } \\
\hline & \multicolumn{2}{|c|}{ Islamic stocks } & Conventional stocks & \multicolumn{2}{|c|}{ Islamic stocks } & Conventional stocks \\
\hline $\begin{array}{l}\text { Without } \\
\text { control }\end{array}$ & \multicolumn{2}{|c|}{1.1844} & 0.5785 & \multicolumn{2}{|c|}{$2.1739^{* * *}$} & 1.2422 \\
\hline With control & \multicolumn{2}{|c|}{$2.8730^{* * *}$} & $3.2848^{* * *}$ & \multicolumn{2}{|c|}{$2.3774^{* * *}$} & $2.3384^{* * *}$ \\
\hline Nobs & \multicolumn{2}{|c|}{1775} & 1775 & \multicolumn{2}{|c|}{140} & 140 \\
\hline \multicolumn{7}{|c|}{ Panel C: Out-of-Sample forecast evaluation [Pre-COVID sample (8/31/2010 to 12/31/2019)] } \\
\hline & \multicolumn{3}{|c|}{ Islamic stocks } & \multicolumn{3}{|c|}{ Conventional stocks } \\
\hline & $h=10$ & $h=20$ & $\mathrm{~h}=30$ & $h=10$ & $h=20$ & $h=30$ \\
\hline $\begin{array}{l}\text { Without } \\
\text { control }\end{array}$ & 1.2089 & 1.2131 & 1.2170 & 0.5390 & 0.4698 & 0.4414 \\
\hline With control & $2.8929^{* * *}$ & $2.8922^{* * *}$ & $2.9057^{* * *}$ & $3.2675^{* * *}$ & $3.2375^{* * *}$ & $3.2305^{* * *}$ \\
\hline Nobs & 1785 & 1795 & 1805 & 1785 & 1795 & 1805 \\
\hline \multicolumn{7}{|c|}{ Panel D: Out-of-Sample forecast evaluation [COVID-19 sample (01/01/2020 to 9/15/2020)] } \\
\hline & \multicolumn{3}{|c|}{ Islamic stocks } & \multicolumn{3}{|c|}{ Conventional stocks } \\
\hline & $\mathrm{h}=5$ & $h=10$ & $\mathrm{~h}=20$ & $\mathrm{~h}=5$ & $h=10$ & $h=20$ \\
\hline $\begin{array}{l}\text { Without } \\
\text { control }\end{array}$ & $2.1228^{* * *}$ & $2.0375^{* * *}$ & $2.1386^{* * *}$ & 1.1527 & 1.0643 & 1.0328 \\
\hline With control & $2.3286^{* * *}$ & $2.2346^{* * *}$ & $2.4255^{* * *}$ & $2.2738^{* * *}$ & $2.2855^{* * *}$ & $2.2912^{* * *}$ \\
\hline Nobs & 150 & 160 & 170 & 150 & 160 & 170 \\
\hline
\end{tabular}

Notes: "Without control" implies a predictive model that does not control for oil price return while "With control" is an extended predictive model that accounts for the oil price variable. The reported statistics in Panel A are obtained from the joint significance test of five lags of the UPE index. For the forecast evaluation, the performance of the UPE-based models ["With control" \& "Without control"] is compared with the historical average that ignores the UPE index. Nobs denotes number of observations. The asterisks ******* \& * imply statistical significance at the $1 \%, 5 \%$ \& $10 \%$ levels, respectively. Values in parentheses represent standard errors while those reported in square bracketsare the $t$-statistics. For the Clark \& West test, the null hypothesis of a zero coefficient is rejected if this statistic is greater than +1.282 (for a one sided 0.10 test), +1.645 (for a one sided 0.05 test), and +2.00 for 0.01 test (for a one sided 0.01 test) (see Clark \& West, 2007). 


\section{REFERENCES}

Al-Awadhi, A. M., Al-Saifi, K., Al-Awadhi, A., \& Alhammadi, S. (2020). Death and contagious infectious diseases: Impact of the COVID-19 virus on stock market returns. Journal of Behavioral and Experimental Finance, 27, 100326. https://doi.org/1 $\underline{0.1016 / j . j b e f .2020 .100326}$

Arnold, S., \& Auer, B. R. (2015). What do scientists know about inflation hedging? The North American Journal of Economics and Finance, 34, 187-214. http s://doi.org/10.1016/i.najef.2015.08.005

Ashraf, D., Rizwan, M. S., \& Ahmad, G. (2020). Islamic Equity Investments and the COVID-19 Pandemic. SSRN Electronic Journal. https://doi.org/1 $\underline{0.2139 / \text { ssrn. } 3611898}$

Baker, S. R., Bloom, N., Davis, S. J., \& Terry, S. J. (2020). COVID-Induced Economic Uncertainty. National Bureau of Economic Research. https://doi.or $\mathrm{g} / 10.3386 / \mathrm{w} 26983$

Clark, T. E., \& West, K. D. (2007). Approximately normal tests for equal predictive accuracy in nested models. Journal of Econometrics, 138(1), 291-311. htt ps://doi.org/10.1016/j.jeconom.2006.05.023

He, P., Sun, Y., Zhang, Y., \& Li, T. (2020). COVID-19's impact on stock prices across different sectors-An event study based on the Chinese stock market. Emerging Markets Finance and Trade, 56(10), 2198-2212. https://doi.org/10.1080/1540496x.2020.1 $\underline{785865}$

Masih, M., Kamil, N. K. M., \& Bacha, O. I. (2018). Issues in Islamic Equities: A Literature Survey. Emerging Markets Finance and Trade, 54(1), 1-26. htt ps://doi.org/10.1080/1540496x.2016.1234370

Narayan, P. K., \& Phan, D. H. B. (2019). A survey of Islamic banking and finance literature: Issues, challenges and future directions. Pacific-Basin Finance Journal, 53, 484-496. https://doi.org/10.101 6/j.pacfin.2017.06.006

Narayan, P. K., \& Popp, S. (2010). A new unit root test with two structural breaks in level and slope at unknown time. Journal of Applied Statistics, 37(9), 1425-1438. https://doi.org/10.1080/02664760903039 $\underline{883}$
Phan, D. H. B., \& Narayan, P. K. (2020). Country responses and the reaction of the stock market to COVID-19-a Preliminary Exposition. Emerging Markets Finance and Trade, 56(10), 2138-2150. http s://doi.org/10.1080/1540496x.2020.1784719

Salisu, A. A., \& Adediran, I. (2020). Uncertainty due to infectious diseases and energy market volatility. Energy Research Letters. https://doi.org/10.46557/00 1c. 14185

Salisu, A. A., \& Adeleke, A. I. (2016). Further application of Narayan and Liu (2015) unit root model for trending time series. Economic Modelling, 55, 305-314. https://doi.org/10.1016/j.econmod.2016.0 $\underline{2.026}$

Salisu, A. A., \& Akanni, L. O. (2020). Constructing a Global Fear Index for the COVID-19 Pandemic. Emerging Markets Finance and Trade, 56(10), 2310-2331. https://doi.org/10.1080/1540496x.2020.1 785424

Salisu, A. A., Swaray, R., \& Oloko, T. F. (2019). Improving the predictability of the oil-US stock nexus: The role of macroeconomic variables. Economic Modelling, 76, 153-171. https://doi.org/1 $\underline{\text { 0.1016/i.econmod.2018.07.029 }}$

Smyth, R., \& Narayan, P. K. (2018). What do we know about oil prices and stock returns? International Review of Financial Analysis, 57, 148-156. https://do i.org/10.1016/j.irfa.2018.03.010

Westerlund, J., \& Narayan, P. K. (2012). Does the choice of estimator matter when forecasting returns? Journal of Banking \& Finance, 36(9), 2632-2640. http s://doi.org/10.1016/j.jbankfin.2012.06.005

Westerlund, J., \& Narayan, P. K. (2015). Testing for Predictability in Conditionally Heteroskedastic Stock Returns. Journal of Financial Econometrics, 13(2), 342-375. https://doi.org/10.1093/ijfinec/nbu001 